\title{
NEWMAN AND FIRST PRINCIPLES: THE NOETIC DIMENSION OF THE ILLATIVE SENSE
}

\author{
ANDREW MESZAROS \\ Catholic University of Louvain (KU Leuven)
}

John Henry Newman's reflections on first principles aim to account for the insurmountable differences between people's worldviews. ${ }^{1}$ The emphasis Newman puts on first principles cannot be overstated. Newman argues for the ultimately determinative role that they play in any dispute. There can be little doubt that Newman was familiar with Aristotle's statement from the Nicomachean Ethics that 'It is thought. . .that the starting-point or principle is more than half the whole matter.' 2 In Newman's words, these 'first elements of thought' are 'half the battle'. 3

Since first principles are so central to the thought of Newman, much has been written on this topic, not only to elucidate Newman's thoughts on the matter, but also to make sense of the term's development in Newman's corpus. ${ }^{4}$ This article will summarize some of the main points of the latest contributors with special attention to the work of Rik Achten. ${ }^{5}$ While his work has much to commend for itself, I will criticize one aspect of it while offering a close reading of relevant passages from Aristotle's Nicomachean Ethics in order to shed light on the noetic aspect of the Illative Sense in its acquisition of first principles.

\section{THE AMBIGUITY OF NEWMANIAN FIRST PRINCIPLES}

In 1851, Newman dedicated an entire chapter to the topic of first principles in his polemical work, The Present Position of Catholics in England, and nearly twenty years later treated the subject once again in his Grammar of Assent (1870). Despite the passage of time, Newman's treatment of first principles in the Grammar had not become any more systematic or clear. Hence, grappling with Newman's understanding of first principles has proven difficult. ${ }^{6}$ In the more mature Grammar - which we consider here - Newman offers extended reflections on first principles in Chapters 4 on Notional Assent and 9 on the Illative Sense.

In the section on 'Presumption' in Chapter 4, Newman defines a first principle as 'the proposition with which we start in reasoning on any given subject-matter' ${ }^{7}$ Here a first principle is considered to be a Notional Assent to a general proposition. This general proposition (e.g., There is an external world; There is One Supreme Master; There is a right and a wrong) is an abstraction or a conclusion that issues from an induction from particular experiences of phenomena. In sum, first principles, at least according to Grammar, Chapter 4, are 'abstractions from particular experiences'.

In Chapter 9, by contrast, first principles are deployed in very specific discourses, and seem to go far beyond any natural intuition. Here, Newman is discussing the way in which the Illative Sense functions at the beginning of any concrete inquiry. First principles, for example, come into conflict within disputes over the 'end and scope of civil society'. 'As a result, first principles here can be quite detailed and particular, such as 'Scripture is the Rule of Faith' or 'a

(C) 2015 Trustees for Roman Catholic Purposes Registered. Published by John Wiley \& Sons Ltd, 9600 Garsington Road, Oxford OX4 2DQ, UK and 350 Main Street, Malden, MA 02148, USA. 
revelation should be conspicuous' ${ }^{10}$ The phrase 'first principles' is, at one point, used interchangeably with 'assumptions'. 11

As a result, there apparently exist two contending understandings of what first principles are. The difference seems quite stark. 'There is an external world' seems to be completely different from 'Scripture is the rule of faith'. Chapter 4's principles seem to be the product of a natural endowment that Newman interchangeably calls instinct or intuition; Chapter 9's seem to be the result of a judgment, usually unconscious, and perhaps, but not always, proceeding from a shrewd, seasoned, and developed mind engaged on a specific subject matter, which is why, among other reasons, this kind of first principle is discussed under the heading of the Illative Sense, itself a species of virtue.

Newman scholars have offered multiple attempts at explaining, or rather categorizing, these apparently diverse species of first principles. Jan Walgrave, for example, characterizes first principles according to their level of psychological adhesion: 'There are more peripheral or more central first principles. There are different layers in the intellectual frame of the mind. ${ }^{12}$ The peripheral or superficial ones can be altered or eliminated with one's mental and personal development, and derive from our personal characteristics or peculiarities and our personal histories. The core or deepest first principles, by contrast, define one's personality and are grounded in our very nature. ${ }^{13}$

In his study on Newman's epistemology, Gerard Casey also attempts to account for Newman's fluctuating use of the term. According to Casey, Newman's first principles can be divided up between 'absolute' and 'relative' first principles, based on the two different functions he gives to Natural Inference. ${ }^{14}$ After extended comparative analysis, Casey concludes that absolute principles are acquired by intuition; relative by inference. Absolute principles include 'There are things external to ourselves' and 'There is a right and a wrong.' On a different plane, relative principles can be recommended by, or follow from, antecedent assumptions and can be unlearned when they are false. Among these are, 'Man is a social being,' and 'Man may defend himself.'

To these distinctions, Walter Jost offers us another distinction between what he calls 'loose' and 'strict' first principles. When Newman uses first principles in the strict sense, he refers to those first principles that are 'groundless' in the sense articulated in The Present Position of Catholics. ${ }^{15}$ The 'looser, more analogical way' in which Newman uses first principles consists of referring to antecedent probabilities, prejudices, and contingent conclusions which, though grounded in previous premises, 'can be used to constitute and explore a problem'. ${ }^{16}$

From the above distinctions, parallels begin to emerge. On the one hand, we have Walgrave's deep, Casey's absolute, and Jost's strict first principles. On the other hand, we have Walgrave's peripheral, Casey's relative, and Jost's loose first principles. That an external world exists can be considered a strict, absolute and deep first principle. That miracles are likely to happen is a loose, relative, and peripheral first principle. ${ }^{17}$ It is true that, despite such a tidy schematization, significant disagreements exist among these three authors, and hence their respective categories cannot correspond completely. ${ }^{18}$ Nevertheless, we do find concurrence in their depiction of a variety of kinds of first principles held by Newman, which has led some scholars to attribute the acquisition of different kinds of first principles to different faculties of mind.

\section{ACHTEN ON NEWMAN AND FIRST PRINCIPLES}

One such scholar is Rik Achten, whose doctoral dissertation, First Principles and Our Way to Faith. A Fundamental-Theological Study of John Henry Newman's Notion of First Principles (1993) is perhaps the most thorough and recent work dedicated to the topic. 
In addition to an informative and incisive survey of Newman's writings on the subject, Achten's most interesting and fruitful contribution to the topic has been his division of Newmanian first principles into Types I, II, III, and IV. The major division lies between Type I first principles and the rest. The distinguishing characteristic of Type I first principles is that they originate in the human being's nature. They are universal and are acquired by a 'universally present instinct'. ${ }^{19}$ 'There are things external to us' and 'There is a right and a wrong' are Type I first principles. The rest (Types II-IV) arise out of culture, history, and personal circumstances. More specifically, Type II's are personal principles; Type III's are culturally and historically conditioned principles, belonging to a group of persons in a certain time; and Type IV's belong to a specific skill, art, or field of knowledge. In short, many are constituted by the professions, credences, opinions, and presumptions discussed in $\mathrm{Ch} .4$ on Notional Assent. ${ }^{20}$

According to Achten, in the first edition of the Grammar (1870), the Illative sense was responsible for the acquisition of all of these first principles. But by the 1889 edition, however, Newman comes to the realization that the noetic faculty (not the Illative sense) is responsible for Type I's. This change is manifest in Newman's 1885 controversy with the Congregationalist minister and academic, Andrew Martin Fairbairn, who would soon become the first principal of Mansfield College, Oxford. ${ }^{21}$

In that controversy, Fairbairn had accused Newman of philosophical scepticism. In response, Newman touched on the existence of the noetic faculty, or nous:

There is a faculty in the mind which acts as a complement to reasoning, and as having truth for its direct object thereby secures its use for rightful purposes. This faculty, viewed in its relation to religion, is, as I have before said, the moral sense; but it has a wider subject-matter than religion, and a more comprehensive office and scope, as being 'the apprehension of first principles,' and Aristotle has taught me to call it $v o \tilde{v} \varsigma$ [nous], or the noetic faculty. ${ }^{22}$

In the above passage, Newman explains in broad terms that the noetic faculty is responsible for acquiring reasoning's antecedents, or the material with which reason goes to work. ${ }^{23}$ Further down, he reiterates,

in such matters the independent faculty which is mainly necessary for its [reasoning's] healthy working and the ultimate warrant of the reasoning act, I have hitherto spoken of as the moral sense; but, as I have already said, it has a wider subject-matter than religion, and a larger name than moral sense, as including intuitions, and this is what Aristotle calls vo $\tilde{v} \varsigma$ $\left[\right.$ nous.$^{24}$

Given this appeal to Aristotelian nous, Achten asserts that Newman, only in 1885 with the Fairbairn controversy, comes to understand 'clearly' that 'we need a special faculty - the nous or the noetic faculty - for the acquisition of those first principles that form the basis of all reasoning. Only then is the noetic faculty clearly distinguished from the Illative sense. ${ }^{25}$

From then on, according to Achten, Newman's account of the acquisition of first principles changes. Whereas before all four types of first principles were acquired by the Illative sense, from 1885 onwards Type I first principles are acquired by nous (or the noetic faculty), and Types II-IV remain beholden, as it were, to the Illative sense. In other words, the Fairbairn controversy marks a turning point in Newman's epistemic development. The consequence of this thesis, however, is that Newman's reflections on prudentia, phronesis, the 'inductive sense', and 'Illative sense', prior to 1885 , would all have to be interpreted in a way that, de facto, rules out the possibility of their having any interpenetration with nous. 


\section{CRITIQUE OF ACHTEN'S POSITION}

What is addressed here is not so much Achten's division of first principles, such as the fact that some spring forth from nature while others emerge from culture. ${ }^{26}$ (There are indeed those first principles which are acquired through a universal instinct, while others are acquired by cultivation, habit, and circumstance.) Rather, what is at issue here is to what extent the Illative sense is a 'separate faculty' from nous. ${ }^{27}$ My contention is that distinguishing between the noetic faculty and the Illative sense is misguided insofar as it imposes an unnecessarily limited understanding of nous onto Newmanian epistemology, and as a result, empties the Illative sense of its noetic dimension. ${ }^{28}$

My argument is essentially that nous is not only responsible for Type I's but also for Types II-IV, and if what Achten observes is true - and I think it is - namely, that the Illative Sense is responsible for acquiring Types II-IV, then it is, by implication, also the case that the Illative Sense has a noetic dimension, or a function whose object is the truth of propositions (and not just an assessment of how one proposition inferentially follows from another, whatever their truth value). What is at stake, then, in Achten's thesis is nothing less than doing justice to the multifaceted faculty that is the Illative Sense.

Here, then, I will provide both external and internal evidence that aims to show how the Fairbairn exchange does not mark a turning point in Newman's thought. This will, in turn, show that Aristotelian nous was already in Newman's mind during his preparations of the Grammar. The evidence below, then, is offered in order to prepare the reader for an engagement with the Nicomachean Ethics, the aim of which will be to illustrate the noetic dimension of the Illative Sense.

\section{External Evidence: Newman's Appeal to Aristotlelian Nous}

In this section, I furnish the following evidence of Newman's awareness of and familiarity with Aristotelian nous prior to his exchange with Fairbairn. Furthermore, I will show how the Fairbairn exchange does not manifest any substantial difference from Newman's prior utilization of nous.

When treating Newman's Theological Papers on Faith and Certainty, Achten considers most, but not all, of the chapters. Among the ones Achten neglects is Newman's lecture on logic, dated 1859. ${ }^{29}$ There Newman mentions Aristotelian nous precisely in the context of differentiating between two kinds of logic: one in the 'strict sense' which is the science of thinking; the other in the 'real' sense, which is the science of knowing, approximating what we might call epistemology. The former has to do with reason considered as an instrument and examines the rightness or validity of inferences - logic proper; the latter has to do with knowing and examines the rightness (or better, the truth) of the premises. This science of knowledge, or truth of the premises, Newman calls 'Noology or Gnoseology from Aristotle's vo $\tilde{\varsigma} \varsigma$ Ethic. lib. 6' ${ }^{30}$

Precisely this distinction is the main current running throughout Newman's response to Fairbairn: the distinction between 'reason' considered as an 'instrument' only, or reason considered in a more broad sense that would be synonymous with the mind. Newman claims to avoid philosophical scepticism because, taken in the first sense, Newman is glad to complement the reasoning 'faculty' with the noetic 'faculty'; and taken in the second sense, 'reason' acquires first principles, according to which it then proceeds to 'reason'. ${ }^{31}$ Hence, Newman makes the same distinction in 1885 as he does in 1859.

The other chapter that Achten neglects is Newman's 'Papers of 1860 on the Evidence for Revelation'. There, Newman is describing the various ways of arguing for the truth of Christianity and what suppositions are necessary on the hearer's part in order for the argument to resonate. Newman writes, 
Since reason in religion, is a reasoning of a religious mind, it is plain that its fundamental axioms will not be intelligible except to religious men...Can this be called a science? Aristotle says an $\varepsilon^{\prime} \pi \imath \sigma \tau \eta^{\prime} \mu \eta$ [Scientific knowledge] is a necessary deduction from principles; and these principles are natural truths and their habit a natural habit. Yet, in like manner, vo $\tilde{v} \varsigma$ may be supernatural - and then this science is not level to the comprehension of any who has not the supernatural habit. ${ }^{32}$

In this interesting passage we read about a nous which Newman describes as supernatural. However, what the principles are that emerge from this supernatural nous is not evident. ${ }^{33}$ Regardless of what, precisely, this supernatural nous is referring to, what is clear is that Newman does not hesitate to use this Aristotelian term in a more unfastened way. A look at the Fairbairn papers here might help: there, Newman seems to use nous in a sense broader than simply natural intuitions. ${ }^{34}$ Newman spends quite some time developing the idea that reasoning's antecedents are acquired by the noetic faculty. He then begins to explain how right reasoning is called 'right' 'because its antecedents are chosen rightly by the divinely enlightened mind, being such as intuitions, dictates of conscience, the inspired Word, the decisions of the Church, and the like'. ${ }^{35}$ In other words, the faculty which is responsible for acquiring reasoning's antecedents, i.e., nous, is used in a wide sense as encompassing a variety of sources for first principles. Some of these surely fall under 'supernatural nous'.

From the above, we conclude that in 1859-1860 Newman already has a clear idea of the distinction between (as he would call it in 1885) the antecedents and the consequents in reasoning. And in 1859, before the publication of the Grammar, he is already associating these antecedents - or the materials of the reasoning process - with Aristotelian nous, however loosely or vaguely. In 1860 he is using nous in a flexible way that encompasses, for example, the 'decisions of the Church'. My contention, then, is that when Newman attributes to the Illative Sense the role of acquiring all sorts of first principles in the Grammar, there exists implicitly a noetic dimension to the Illative sense's acquisition of them all already in the first edition of 1870 .

\section{Internal Evidence: A Closer look at the Grammar of Assent}

To support his contention that the Illative Sense does not acquire Type I first principles, and that this function is, after 1885, attributed to the noetic faculty, Achten appeals to some secondary literature. ${ }^{36}$ His appeal to A.J. Boekraad, however, does little to support his case, as Boekraad merely states that 'we have no means of determining' whether the 'Illative sense or moral sense and the 'nous' of Aristotle are totally equivalent'. ${ }^{37}$ He also appeals to Ian Ker, who in his notes claims that 'Neither the Illative sense nor logic can determine the first principles on which all knowledge rests.' Ker goes on to cite some of the Theological Papers and pp. 268-270 of the Grammar. ${ }^{38}$ In those pages, however, Newman tells us that that which cannot determine first principles is (formal) inference or logic. And the Theological Papers are precisely the text under dispute here. $^{39}$

In addition to secondary literature, Achten also points to the major alterations in the updated 1889 version of the Grammar that, he claims, corroborate his thesis. He observes that the most significant portions of omissions and rewrites are in places which discussed first principles. An examination of these passages, however, fails to truly substantiate the claim that, in the 1889 edition nous now, rather than the Illative sense, is responsible for acquiring first principles.

The first key passage cited by Achten is the first paragraph of the section entitled 'The Range of the Illative Sense'. The following passage from the 1870 edition, is omitted from the 1889 edition: 
Since ratiocination, viewed in itself, is an instrumental faculty, though in fact ever embodied and acting in some definite subject-matter; such also is the Illative Sense, which is its virtue or perfection. It is only concerned with the soundness of the reasoning; but for the truth of a conclusion we must have recourse to the truth of the premises. It is a capacity of entering with instinctive correctness into principles, doctrines, and facts, whether they be true or false, and of discerning promptly what conclusion from them is necessary, suitable, and expedient, if they are taken for granted; and this, either by means of a natural gift or from long habituation to those various circumstances. ${ }^{40}$

While the deletion of this passage - a passage which seems to imply that the Illative sense is responsible for 'entering with instinctive correctness into principles...' - might suggest that Newman is now denying it, he seems to say something equivalent in the new version:

It is the ratiocinative mind itself. . however simply in its form and sure in operation, by which we are able to determine, and thereupon to be certain, that a moving body left to itself will never stop, and that no man can live without eating. . .It is to the living mind that we must look for the means of using correctly principles of whatever kind, facts or doctrines, experiences or testimonies, true or probable, and of discerning what conclusion from these is necessary, suitable, or expedient, when they are taken for granted; and this, either by means of a natural gift, or from mental formation and practice and long familiarity with those various starting points. ${ }^{41}$

So while the passage from 1870 in its precise form is omitted from the 1889 edition, the above passage shows how relevant portions of the previous were reproduced. Is there, for example, a significant difference between 'entering with instinctive correctness into principles etc'. (1870) and 'discerning. . .when these [principles etc.] are taken for granted' (1889)? And even if it did indicate a difference, surely this later passage would seem to give the Illative Sense an expanded, not diminished, noetic function.

The lengthiest passage that was taken out in the new edition - some three and a half pages was not so much omitted as condensed. ${ }^{42}$ Newman manages to shorten the original to approximately two pages. He also sets up a clearer structure, offering the reader some signposts for what is to follow; such signposts were absent in the 1870 edition. The single most prominent point in the original is retained in the rewrite, albeit condensed by leaving out examples. The retained point is that verbal argumentation and analysis are incapable of laying hold of those 'first elements of thought' with which reasoning proceeds, and that these 'first elements' are affected by 'personal characteristics' that potentially set two individuals at variance with one another. ${ }^{43}$ One point omitted in the new edition is Newman's lengthy paragraph about how the Illative Sense is employed in one's approach to facts and personal issues. 'And thus', Newman wrote in 1870, 'it is the instrument of induction from particulars, and determines what are general laws, and what conclusions cannot reach beyond bare probability...it is by the Illative Sense that we reason out, from the data we possess, that nature is uniform...'

Two points are of interest here. First, Newman mentions that the Illative Sense induces general laws from particular phenomena. If the deletion of this claim is meant to show that Newman no longer holds it, then why is it the case that, in Newman's 1889 rewrite of the first omitted passage noted above (Ker 340 (1870 ed. 353) it is the ratiocinative mind that is responsible for ascertaining the truth that 'a moving body left to itself will never stop' and 'no man can live without eating'? Are these not precisely general laws induced from particular phenomena whose truth is ascertained, not by logical argument, but by the Illative sense? In other words, the rewrite shows that Newman's deletion need not - and in fact, did not - indicate a change in his epistemology. 
Secondly, in the above passage in question, the example Newman gives of a 'general law' is that 'nature is uniform'. But if this omission were due to a change in Newman's conception of the acquisition of first principles, then it would be reasonable to suppose that a corresponding change in his section on 'Presumption' in Ch. 4, which also deals with this principle, would also have been made. As it is, Newman's reflections in that section are substantially unchanged: the uniformity of nature is a general law, 'derived from experience' and 'accepted with ... a presumption'. ${ }^{44} \mathrm{He}$ has yet, in Ch. 4 , to associate the acquisition of this principle of the uniformity of nature with the Illative Sense, but that can be explained by the fact that he has yet to introduce the Illative Sense at all in Ch. 4. In sum, the deletion of the passage 'It [the Illative Sense] is the instrument of induction from particulars. .' need not imply that Newman, in 1889, denies it. ${ }^{45}$

At this point, then, it should also be noted that the subsection considering the function of the Illative Sense at the beginning of the inquiry - the most relevant subsection wherein one would expect significant changes were Achten's thesis to be correct - is left substantially unchanged with the exception of one passage, which is omitted 'Should it be objected...etc." ${ }^{46}$ In this lengthy paragraph of about half a page, the only mention of first principles is in a clause in which Newman aims to defend the utility of the Illative Sense despite the intense disagreement in historical disputes. 'It is not the fault of the Illative Sense, that men differ in first principles,' Newman writes. The principles in question, however, are those which historians deploy in their interpretation of historical data, such as which points demand proof, and which merit presumption. That Newman deleted the passage regarding the Illative sense's not being at 'fault' for this disagreement in no way implies that the Illative Sense, rather than the noetic faculty, is solely responsible for first principles of Types II-IV.

We ought to remember that Newman was already familiar with Aristotelian nous prior to the first edition of the Grammar. If one seeks an explanation for the omissions in the 1889 Grammar, Newman's confrontation with this distinction cannot be it. ${ }^{47}$

Before we move to the next section, we should note that there is good reason to suppose that a noetic dimension belongs to the Illative Sense, despite the fact that Newman never uses the word 'noetic' in the Grammar (in either edition). When Newman states in the newer edition that the Illative Sense 'appeals to no judgment beyond its own, and attends upon the whole course of thought from antecedents to consequents...', ${ }^{48}$ he does so without qualification or exception. We should recall that the language of 'antecedent' and 'consequent' is precisely that which Newman uses in his response to Fairbairn when he introduces nous as that faculty which deals with the antecedents of reasoning. And yet, in the revised edition of the Grammar we have Newman stating that the Illative Sense deals with both. Nous and the Illative Sense, it seems, must be interconnected in such a way that certain mental activities that are attributed to the Illative Sense are also noetic.

\section{ARISTOTELIAN NOUS AND NEWMANIAN FIRST PRINCIPLES}

For Achten, the noetic faculty's object is Type I first principles, while Types II-IV are the province of the Illative sense whose rootedness in Aristotelian phronesis is well-known. The question underlying this section is, Does nous only account for Type I first principles? As Achten states, Type I's are 'spontaneous' and 'without intermediary'. ${ }^{9}$ 'There is a right and a wrong' is an inference (or more accurately, an intuition) stemming from the experience(s) of injustice, cruelty etc. . .but if nous is what is needed to acquire only such fundamental first principles of 'universal reception', why is it necessary, as Newman uses Aristotle to exhort, to: 
attend to the undemonstrable dicta and opinions of the skillful, the old and the Practically Wise, no less than to those which are based on strict reasoning, because they see aright, having gained their power of moral vision from experience. ${ }^{50}$

It seems that not simply untutored experience, but some version of cultivated, seasoned experience on a given subject matter, is what helps us acquire the requisite first principles in a given field, and this acquisition can be attributed to nous.

What I aim to show is not that the Illative Sense is responsible for acquiring Type I principles (which are acquired by an intuition that Newman would qualify as 'noetic', no doubt), but rather that there can be a properly noetic dimension to those instances where the Illative Sense acquires first principles of Types II-IV. In other words, the functioning of the Illative Sense at the beginning of the inquiry is 'shot through', as it were, with nous, and therefore the noetic faculty is not limited to acquiring Type I first principles. In order to show this one need only reflect on the role that nous plays in its intersection with phronesis in Aristotle's Nicomachean Ethics. For one, the famous section from Aristotle that Newman quotes is in fact located precisely in the context of discussing the relationship between nous and phronesis.

\section{Nous and Phronesis in Book VI of the Nicomachean Ethics}

The Nicomachean Ethics is the key Aristotelian text for understanding Newman's creative application of Aristotelian thought in the Grammar. In Book VI of the Ethics Aristotle discusses

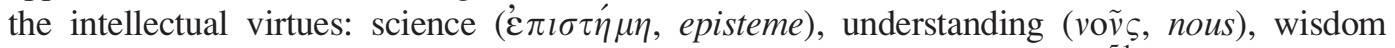

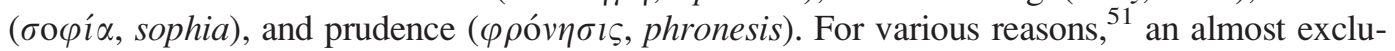
sive attention to understanding (nous) as that which gives us the 'universal' and 'necessary' first principles for achieving science has prevailed. In reality, however, nous cannot be reduced to that which apprehends the definitions of things whereby the universal principles for scientific demonstration are acquired for, in addition to these scientific syllogisms, Aristotle deploys nous in practical matters, especially in Book VI, Ch.11 (nous here being rendered as "intuitive reason'):

For not only must the man of practical wisdom know particular facts, but understanding and judgement are also concerned with things to be done, and these are ultimates. And intuitive reason [nous] is concerned with the ultimates in both directions; for both the first terms and the last are objects of intuitive reason [nous] and not of argument, and the intuitive reason [nous] which is presupposed by demonstrations grasps the unchangeable and first terms, while the intuitive reason [nous] involved in practical reasonings grasps the last and variable fact, i.e., the minor premiss. For these variable facts are the starting-points for the apprehension of the end, since the universals are reached from the particulars; of these therefore we must have perception, and this perception is intuitive reason $[$ nous $] .{ }^{52}$

From this passage it becomes clear that, in the Nicomachean Ethics nous has a practical as well as a scientific function. Nous acquires the particulars of what has been called a "practical syllogism'. Accordingly, the major premise is a rule or principle (arche) e.g., 'That which is pleasant is to be done'; the minor is the particular case hic et nunc as an instance of the major principle, e.g., 'This is pleasant.' For Aristotle, it is nous - rendered 'intuitive reason' by Ross, and 'Intuition' by Chase - which apprehends this singular. Nous, as a result, takes on two roles: apprehending necessary universals and apprehending particular singulars by perception ( $\alpha i \sigma \theta \eta \sigma l \varsigma)$.

This perception is a 'seeing', but in a figurative way. The point is that when the sensible person - or 'prudent man' - the one who is judicious, who possesses common sense, sees a 
principle active in a given particular, he 'perceives' it, and he does so immediately and intuitively; ${ }^{53}$ he has nous, 'good sense', or 'understanding'. It is important to recognize here that nous is now applied, not to speculative demonstrations about necessary things, but to 'those [things] in respect of which a man might doubt and deliberate ${ }^{, 54}$; this is, in short, the concrete realm in which Newman is so interested.

\section{Clarifying Practical Nous}

The single most distinctive mark of an 'intuition' for Newman, is that it is immediate - not that it is universal and irresistible. ${ }^{55}$ This is also precisely the mark attributed to nous by scholars of Aristotle. ${ }^{56}$ While universality and irresistibility are marks of Type I first principles, in his papers entitled 'Assent and Inference' Newman claims that intuitions can be conditioned by age, sex, and talent, and that this conditioning affects the extent to which certain intuitions are received. ${ }^{57}$ In other words, Newman seems to be implying that Types II-IV first principles are also intuited. Far from reserving intuition to Type I's, Newman writes:

Intuition, though it is the absolute assent which we are naturally capable of giving to the first principles of all knowledge, may be exercised on other truths; it is the gift of the few as well as of the multitude. It is the exercise of a faculty, which is stronger or weaker in this man or that, but of which in every state truth is the object. ${ }^{58}$

Attention should be drawn here not only to the extension of intuitions beyond Type I first principles, but also to the explicit demarcation of its object: namely, truth. In other words, these intuitions are responsible for ascertaining the truths of reasoning's antecedents, precisely the role given to nous by Newman in his response to Fairbairn.

In Newman's response to Fairbairn, it should be mentioned that Newman is consulting D.P. Chase's translation of Aristotle, the footnotes of which can be helpful in illuminating Newman's thought. ${ }^{59}$ Having summarized the functioning of nous in the practical realm, we are better positioned to understand Chase's footnote when he writes,

There are cases where we must simply accept or reject without proof: either when Principles are propounded which are prior to all reasoning, or when particular facts are brought before us which are simply matters of aisthesis. Aristotle here brings both these cases within the province of nous, i.e. he calls by this name the Faculty which attains Truth in each. ${ }^{60}$

Chase again:

There are cases both of principles and facts which cannot admit of reasoning, and must be authoritatively determined by nous. What makes nous to be a true guide? only practice, i.e. Experience. $^{61}$

In relation to first principles it is essential to recognize that 'there are first principles in practical reason ${ }^{62}$ and that these first principles - far from being universal, necessary, and irresistible - are acquired by practice, by experience; and yet, they are nevertheless recognized by nous.

Nous, in addition to deliberation ( $\varepsilon \dot{v} \beta$ ov $\lambda i \alpha)$, judiciousness $(\sigma \dot{v} v \varepsilon \sigma l \varsigma)$, and exhibiting equitableness $(\gamma v \omega ́ \mu \eta)$, is considered in its practical form a subsidiary of phronesis. By this, I mean that all of these are considered to be functions of phronesis, and that all of these are attributed to one who is denoted as 'practically wise'. 63

Crucial here, I would suggest, is the reliance of these other phronetic functions on nous. Judiciousness, for example, which amounts to judging well of what someone else says about matters concerning practical wisdom, ${ }^{64}$ is impossible without apprehending the particulars in question. 
In other words, this practical nous is a critical component of what it means to be $\varphi \rho$ ó $\iota \iota \mu$ s, or a prudent person.

\section{The Noetic Dimension of the Illative Sense in Acquiring Principles of Types II-IV}

Despite Newman's descriptions of the Illative Sense as the power of 'judging and concluding, when in its perfection', 65 it would be wrong to reduce the Illative Sense to that which assesses the legitimacy of various inferences. For the capacity to judge of a concrete question already supposes that action of the mind which, according to Newman, 'detects', 'illustrates', 'establishes', and 'eliminates' 'those first elements of thought' which are 'half the battle in the inference'. ${ }^{66}$ Without a noetic dimension attributed to the Illative Sense, it makes little sense for Newman to declare that this virtue 'has its function in the beginning, middle, and end' of all inquiry. ${ }^{67}$

Admittedly, it is not at all obvious that Aristotle's examples of the functioning of practical nous are particularly enlightening for understanding Newman. One such example is: 'All water that weighs heavy is bad' and 'This particular water weighs heavy'. ${ }^{6}$ Newman's first principles of religious apologetic are prima facie very different. What is seminal in Aristotelian practical syllogisms, however, is that the exercise of nous enables one to either acquire or to be better able to accept the first principles of which the particulars perceived are an instantiation. In the words of Chase, 'By habitually acting on the Minor Premiss. . . a man comes really to hold the Major Premiss. ${ }^{69}$ What is more, these particulars might not exist within the domain of a 'universal instinct', but within the domain of particular experiences and expertise.

Now it would be a stretch of the imagination to suggest that Newman is repeating Aristotle's exhortation to attend to the skillful, old, and wise in order to substantiate one's own conviction about the existence of an external world or about there being a right and a wrong. What is at issue here are, in fact, precisely the more delicate and controversial first principles, or Achten's Types II-IV. Society's seasoned individuals are those who have nous or understanding, or good sense in a particular subject matter, and we consult them, not on the obvious, but on the right course of action (or inference) in that particular field; for Newman we go to them also for the sake of the principles which they have acquired and have, over many years, thought to be dependable. Newman's echo of Aristotle makes most sense if we posit a noetic dimension to the Illative Sense when it functions at the beginning of an inquiry.

If one accepts Newman's transference of phronesis from the realm of praxis to the realm of verity (i.e., from questions of 'what is to be done' to 'what is (was) the case?'), then should not the practical functioning of nous also undergo this creative transference? And if we bear in mind one of Newman's favorite adages, we are obliged to seek out the one who has expertise in that which we are seeking to know more about: 'Cuique in arte suâ credendum est'. ${ }^{70}$ In other words, if we seek to know more about religion, for example, we ought to go to those who have experiences of it.

What is at issue is not simply apprehending a particular, such as experiencing the drinking of water as invigorating and then habituating oneself into affirming that water gives energy. As social beings, humans are given to experiencing not only things, but also the assessments and evaluations which their surrounding culture attaches to them, thereby confirming or reinforcing individuals' preliminary convictions. Experiential or cultivated nous, then, not only touches what we make of an external world, but also what we make of gossip, testimony, hearsay, adages, and the like, which, in turn, might bear on highly existential and religious questions.

Examples of these might include, 'a revelation is possible', 'testimonies of an extraordinary religious experience ought to be taken seriously', 'miracles happen', 'God's ways are not our ways', and even 'A God who wants to be known will provide the requisite means.' Such 
propositions are not so much argued for as they are assented to by way of an intuition, even if that intuition is far from irresistible or universally adhered to. They are not necessarily the fruits of a series of inferences, but of 'insights' or 'intuitions' of someone in touch with his or her conscience. They are not arbitrary assumptions with which we start an inquiry; rather, they can be conceived of as implicit assumptions which are based on past experiences and which have proven to be effective interpretive guides in dealing with a certain subject matter. And these are legitimately attributed to nous.

\section{CONCLUSION}

Newman neither uses the word 'noetic' in the Grammar, nor does he explicitly divide up his first principles into the way in which Achten does. Hence, from the outset it is difficult to assess Achten's thesis.

We saw that Newman was already familiar with the noetic faculty and that the alterations between the two editions of the Grammar did not corroborate the claim that Newman's position changed. In highlighting the function of practical nous in the Nicomachean Ethics, I showed that a nous which can be cultivated, which is rooted in experience, and which is deployed in the practical sphere, is materially equivalent to the functioning of the Illative Sense when it deals with more complex assumptions beyond the obvious Type I principles. In short, the Illative Sense has, I contend, a noetic dimension, and hence, reserving the 'noetic faculty' to the acquisition of Type I first principles unnecessarily compartmentalizes the kind of mental activity in question: namely, ascertaining the truth of reasoning's antecedents.

\section{Notes}

1 Newman, Lectures on the Present Position of Catholics in England, pp. 283-4. Hereafter, Prepos. All works of Newman refer to the Longmans uniform edition and follow Rickaby's abbreviations.

2 The Nicomachean Ethics of Aristotle: A New Translation, Mainly from the Text of Bekker. With Explanatory Notes, (Oxford: William Graham, 1847), 21. Hereafter, E.N. (Chase ed.). Passages from Aristotle's Nicomachean Ethics cited simply as E.N., come from W.D. Ross-Bywater translation in The Works of Aristotle, Vol. IX (Oxford: OUP, 1915). Newman consults the Chase translation during the Fairbairn Controversy. Interestingly, Chase, having been a fellow at Oriel College, also quotes Newman in his preface, p. iii. When Bekker numbers are given, the line numbers are provided on multiples of 5. (E.g., 1143a5-1143a10 is given for a text that might appear in line 6 or 7 etc.)

3 Newman, An Essay in Aid of a Grammar of Assent, p. 361. Hereafter, G.A. Cf. pp. 311-2.

4 Cf. Philip Flanagan, Newman, Faith and the Believer (London: Sands \& Co. Ltd., 1946), pp. 66-91; Robin Selby, The Principle of Reserve in the Writings of John Henry Cardinal Newman (Oxford: Oxford University Press, 1975), pp. 75-88; Jan H. Walgrave, J. H. Newman. His Personality, His Principles, His Fundamental Doctrines, Course Lectures (Katholieke Universiteit Leuven, 1975-1977), pp. 55-81; Thomas Norris, Newman and His Theological Method: A Guide for the Theologian Today (Leiden: E.J. Brill, 1977), pp. 120-36; Gerard Casey, Natural Reason: A Study of the Notions of Inference, Assent, Intuition, and First Principles in the Philosophy of John Henry Cardinal Newman (New York: Lang, 1984); M. Jamie Ferreira, Scepticism and Reasonable Doubt: The British Naturalist Tradition in Wilkins, Hume, Reid and Newman (Oxford: Clarendon Press, 1986), pp. 145-71. Jost, Rhetorical Thought in John Henry Newman (Columbia, SC: USC Press, 1989), pp. 47-8; Terrence Merrigan, Clear Heads and Holy Hearts: The Religious and Theological Ideal of John Henry Newman, Louvain Theological and Pastoral Monographs, 7 (Leuven, Peeters \& W.B. Eerdmans, 1991), pp. 212-5.

5 Rik Achten, First Principles and Our Way to Faith: A Fundamental-Theological Study of John Henry Newman's Notion of First Principles (Rome: Pontificia Universitas Gregoriana, 1993).

6 Walter Jost, Gerard Casey, and Jamie Ferreira, among others, have made attempts to untangle the terminological mess all the while keeping in mind that Newman's thoughts on the subject developed.

7 G.A., p. 60. 
8 G.A., p. 65.

9 G.A., p. 379.

10 G.A., pp. 378-9.

11 G.A., p. 379.

12 Walgrave, J.H. Newman, p. 56.

13 Walgrave, J.H. Newman, p. 55-7. Cf. Merrigan, Clear Heads and Holy Hearts, p. 214, referring to Walgrave, 'Newman's beschrijving en verantwoording van het werkelijk denken', Tijdschrift voor Philosophie 1 (1939), pp. 544-5.

14 See Ch. 4 of Casey, Natural Reason. There, Casey makes the case for a distinction between Natural Inference as a kind of inference, and Natural Inference as an intuition. See esp. pp. 43-51; p. 68.

15 Prepos., 278.

16 Jost, Rhetorical Thought, p. 49. Cf. pp. 46-54.

17 While first principles have no grounds, they do admit of 'recommendation'. Some principles are superior to others. See Prepos., pp. 298-306.

18 Casey and Jost, for example, seem to disagree on the nature of Induction. For Casey, inductions are intuitions, not inferences. As an ultimate consequence, Casey's absolute first principles have no grounds, while Jost's strict first principles do have grounds!

19 Achten, Frist Principles, p. 141.

20 Achten, First Principles, pp. 136-47. Cf. Appendix 1 on p. 278.

21 Before Oxford, Fairbairn was principal of Airedale College, Bradford, a non-conformist college. For a more substantive account of the controversy, see William B. Selbie, Life of Andrew Martin Fairbairn (London: Hodder and Stoughton, 1914), pp. 202-11 and Ian Ker, John Henry Newman: A Biography (Oxford: Oxford University Press, 1990), pp. 742-3. Selbie is partial to Fairbairn; Ker to Newman.

22 Cf. T.P., p. 153.

23 T.P., pp. 154-5.

24 Cf. T.P., p. 153.

25 Achten, First Principles, pp. 140-1. Cf. Achten's summary and interpretation of the Fairbairn controversy in view of its implications for the development of Newman's epistemic theory, pp. 125-7; 116-120.

26 Even this distinction must be qualified. In making such a 'nature versus nurture' distinction, one has to be able to account for those cases in which the former inhibits, obstructs, or obscures that which comes from the latter.

27 Achten, First Principles, pp. 140-1.

28 It is true that Newman differentiates between the noetic faculty and the reasoning faculty, calling one an 'independent faculty'. But it should be noted that the counterpart to the noetic faculty in Newman's response to Fairbairn is not the Illative Sense, but 'reasoning' understood in a strict sense as an instrument.

29 T.P., pp. 51-62.

30 T.P., pp. 54-5.

31 T.P., pp. 140-2; 154-5.

32 T.P., p. 88.

33 My conjecture is that this supernatural or religious nous is synonymous with conscience or the moral sense. It is the converse of what he says later in 1885: this given faculty which he has called the 'moral sense' has in fact a wider subject-matter than religion, and that this faculty's wider denomination is nous. That being said, this 'supernatural nous' does not preclude the articles of the creed in the Thomistic sense of 'first principles' of theology. This, however, does not seem to be on Newman's mind in this particular passage.

34 T.P., p. 153. Newman says that the noetic faculty 'includes' intuitions; but he does not limit it to them. And while other faculties contribute to reasoning's antecedents, the noetic faculty is the one that is 'mainly necessary'. Cf. T.P., p. 155: 'In questions of religion it is mainly the noetic, sometimes another; in mathematics, the noetic faculty only.'

35 T.P., p. 154.

36 Achten, First Principles, 126-7n445.

37 A.J. Boekraad, The Personal Conquest of Truth according to J. H. Newman (Louvain: Nauwelaerts, 1955), p. 302n.

38 An Essay in aid of a Grammar of Assent, ed. Ian T. Ker (Oxford: Clarendon Press, 1985), p. 381, hereafter cited as Ker. See note on 'ratiocinative talent'.

39 In addition to the Fairbairn papers, Ker also refers to passages from Newman's 'Assent and Intuition' (T.P., 63-80, pp. 69-72). There it is clear that the foundation of all knowledge, for Newman, are intuitions, but this does not substantiate the claim that these intuitions have nothing to do with the Illative Sense. And, as 
they are written prior to the first edition of the Grammar, it becomes difficult to make the case that these intuitions were something separate from the Illative Sense when it is claimed, as Achten does, that the Illative Sense was responsible for Type I first principles! Achten also appeals to S. A. Grave, Conscience in Newman's Thought (Oxford: Clarendon Press, 1989), p. 36n7, p. 54n16, and p. 66. Grave, however, only seems to substantiate the fact that the moral sense is the religious application of nous and that not all what Newman calls first principles are intuited.

40 Ker, p. 340 (1870 ed., p. 353). The 1870 edition used was published in London: Burns, Oates \& Co., 1870.

41 G.A., pp. 360-361.

42 Ker, pp. 340-2 (1870 ed., pp. 353-7).

43 G.A., pp. 361-2.

44 G.A., p. 68.

45 While Achten does not maintain this explicitly, I see no other reason why the deletion of this passage could potentially support his case.

46 Ker, p. 342 (1870 ed., pp. 305-6).

47 Other scholars can and should examine these omitted passages. As far as I am concerned, Achten's appeal to them fails to convince. While there is no space here to explore possible explanations for Newman's alterations, one can note in passing that much in these passages are repeated elsewhere in the book. In short, the issue may be as simple as redundancy (rather than a shift in Newman's thinking).

48 G.A., p. 362.

49 Achten, First Principles, p. 136.

50 E.N., 1143b10-15. Newman quotes this passage in G.A., 341.

51 Among them, in Aristotle's short summaries of the intellectual virtues, nous is presented as that state by virtue of which one acquires the principles of demonstration (1140b30-1141a10). This is corroborated with Aristotle's logic in the Analytics. What is surveyed here takes into account the section exploring the relationship between phronesis and nous (1143a20-1143b20).

52 E.N., 1143a30-1143b10.

53 See. H.H. Joachim, Aristotle. The Nicomachean Ethics (Oxford: Clarendon Press, 1951), pp. 211-213.

54 E.N. (Chase ed.), 1143a5. Ross' rendering: 'things which may become subjects of questioning and deliberation'.

55 T.P., pp. 68-69.

56 E.g., Joachim, Aristotle, p. 213.

57 T.P., p. 69.

58 T.P., p. 69.

59 T.P., 153. Newman's footnote refers to Chase's A First Logic Book. This, it seems, is a mistake. It should be referring to Chase's translation of the Nicomachean Ethics.

60 E.N. (Chase ed.), p. 223n $t$.

61 E.N. (Chase ed.), p. $224 \mathrm{n} w$.

62 E.N., 1142a15-20.

63 E.N., (Chase ed.), pp. 222-223. Chase says that phronesis is 'equivalent to' them all.

64 E.N., 1143a1-20.

65 G.A., p. 353.

66 G.A., p. 361.

67 G.A., p. 361.

68 E.N., 1142a20-25

69 Nicomachean Ethics, ed. Chase, pp. 223-224n v. Cf. p. 8n $t$.

70 G.A., 341. Also cited in T.P., pp. 22, 26, 88, 92. 